\title{
Nanotherapeutics With Anthracyclines: Methods of Determination and Quantification of Anthracyclines in Biological Samples
}

\author{
E. KOZIOLOVA ${ }^{1^{*}}$, O. JANOUSKOVA ${ }^{1^{*}}$, P. CHYTIL $^{1}$, M. STUDENOVSKY ${ }^{1}$, L. KOSTKA ${ }^{1}$, \\ T. ETRYCH ${ }^{1}$
}

*These authors contributed equally to this work.

${ }^{1}$ Institute of Macromolecular Chemistry, Academy of Sciences of the Czech Republic, Prague, Czech Republic

Received June 10, 2015

Accepted July 16, 2015

\begin{abstract}
Summary
Anthracyclines, e.g. doxorubicin, pirarubicin, are widely used as cytostatic agents in the polymer nanotherapeutics designed for the highly effective antitumor therapy with reduced side effects. However, their precise dosage scheme needs to be optimized, which requires an accurate method for their quantification on the cellular level in vitro during nanocarrier development and in body fluids and tissues during testing in vivo. Various methods detecting the anthracycline content in biological samples have already been designed. Most of them are highly demanding and they differ in exactness and reproducibility. The cellular uptake and localization is predominantly observed and determined by microscopy techniques, the anthracycline content is usually quantified by chromatographic analysis using fluorescence detection. We reviewed and compared published methods concerning the detection of anthracycline nanocarriers.
\end{abstract}

\section{Key words}

Anthracycline • Nanocarrier • Quantification

\section{Corresponding author}

E. Koziolova, Institute of Macromolecular Chemistry, Academy of Sciences of the Czech Republic, Heyrovský Sq. 2, 16206 Prague 6, Czech Republic. E-mail: koziolova@imc.cas.cz

\section{Introduction}

Anthracyclines belong to the most potent cytostatics ever developed and various types of cancer are successfully treated by them. However, their administration may lead to cardiomyopathy and congestive heart failure. The first anthracycline, daunorubicin (DNR), was isolated from the Streptomyces peucetius in the $1960 \mathrm{~s}$ and it is currently used in the treatment of acute leukemia (Coombs et al. 2015). The most common anthracycline, doxorubicin (DOX), which is believed to be one of the most powerful cytostatic agents, was developed shortly after. Until now, several new anthracyclines, e.g. epirubicin (EPI), pirarubicin (PIR), with enhanced antitumor activity and improved pharmacological profile have been synthesized and introduced into clinical practice (Minotti et al. 2004).

Nowadays, modern medicine requires targeted therapy, especially in cancer treatment. Over the past few decades, the targeted therapy using drug nanocarriers has been studied in detail. Anthracyclines, especially DOX, have served as active agents of various nanocarriers in cancer therapy (Wicki et al. 2015). The drug nanocarriers are accumulated in the solid tumor tissue due to the Enhanced Permeability and Retention effect (Matsumura and Maeda 1986) resulting in increased antitumor activity when compared with the free drug. The majority of the DOX-bearing nanocarriers utilize physical entrapment of the hydrophobic DOX molecules into the hydrophobic core (Deepa et al. 2014). However, the premature drug release from these nanocarriers in blood may lead to severe toxic effects on the healthy tissue and to decreased antitumor activity. 
The polymer conjugates with anthracyclines bound via biodegradable spacers enable the stimulisensitive release in the target tissue and prevent the premature drug release during blood circulation. Their benefits in cancer therapy have been proved in vivo and also in clinical trials. Unfortunately, their introduction into clinical practice is still awaited.

The clinical efficiency of anthracyclines has been proved to be related to their actual concentration in the tumor tissues (Speth et al. 1988). Moreover, their overall toxicity is dependent on the plasmatic concentration profile. Various analytical methods for the determination and quantification of free anthracyclines in the biological samples have been reviewed (Loadman and Calabrese 2001, Zagotto et al. 2001). Although anthracyclines are frequently used in diverse nanocarriers, the reviews dealing with the methods of the determination and quantification of the anthracycline nanocarriers are rare. The majority of the published methods analyzing these nanocarriers determine the total drug amount, both released and not released. Here, we summarize the methods for the determination of free and nanocarrier bound anthracyclines.

\section{Anthracyclines and their nanocarriers}

Since DOX is the most frequently used anthracycline in the clinics and in designing the new drug delivery systems, numerous methods of its determination in biological samples have been published. Its biodistribution has been compared with the biodistribution of other anthracyclines, e.g. DNR, idarubicin (IDA), EPI, PIR (Nagasawa et al. 1996, PérezRuiz et al. 2001) or with its active metabolites (Anderson<smiles>[R]C(=O)[C@]1(O)Cc2c(O)c3c(c(O)c2[C@@H](OC2CC(N)C([R2])C(C)O2)C3)C(=O)c2c(OC)cccc2C1=O</smiles>

Fig. 1. The chemical structures of anthracyclines. et al. 2002).

Numerous nanocarriers with anthracyclines have been synthesized and tested in vivo. Their biodistribution is crucial for the enhanced antitumor activity and for the minimized side effects. The biodistribution of the released drug and the drug carrier has been determined for the polymer-coated liposomes (Goren et al. 2000, Xiong et al. 2005, Li et al. 2009), among others, Doxil (Uster et al. 1998, Laginha et al. 2005); micelle-forming block polymers (Yoo and Park 2001, Shuai et al. 2004, Dai et al. 2008, Cuong et al. 2010, Wu et al. 2012); nanoparticles (Janes et al. 2001, Park et al. 2009, Jin et al. 2012); nanoparticles codelivering DNA or RNA (Chen et al. 2010, Meng et al. 2010); modified polypeptides (Yang et al. 2006) with physically entrapped anthracyclines. The physical entrapment of the drug cannot prevent the drug leakage during blood circulation and during the processing of the biological sample in the course of the drug content quantification. The attention should be paid to the used procedure, its duration and the applied excipients.

The nanocarrier with the anthracycline covalently attached via a spacer degradable in the tumor tissue or cells can decrease the drug leakage from the nanocarrier during blood transportation and enable the drug release in the target site (Fraier et al. 1995, Etrych et al. 2011). The carrier structure can be based on the watersoluble and biocompatible polymer, e.g. copolymers of $N$-(2-hydroxypropyl)-methacrylamide (HPMA) (Fraier et al. 1995, Etrych et al. 2011) or polyethylene glycol (PEG) (Rodrigues et al. 1999), proteins (Kratz et al. 1998, Beyer et al. 2001) and synthetic polypeptides (Dreher et al. 2003).

\begin{tabular}{ccc}
\hline & $\mathrm{R} 1$ & $\mathrm{R} 2$ \\
\hline $\begin{array}{c}\text { Daunorubicin } \\
\text { (DNR) } \\
\begin{array}{c}\text { Doxorubicin } \\
\text { (DOX) }\end{array}\end{array}$ & $-\mathrm{CH}_{3}$ & $-\mathrm{OH}$ \\
Pirarubicin (PIR) & $-\mathrm{CH}_{2} \mathrm{OH}$ & $-\mathrm{OH}$ \\
\hline
\end{tabular}




\section{Methods of anthracycline determination and quantification}

Modern techniques enable the highly sensitive anthracycline detection in strongly diluted samples. However, these samples require very careful handling. Thus, prior to the review of the detection techniques, the anthracycline characteristics and possible complications concerning sample handling and pretreatment will be discussed.

\section{Anthracycline characteristics important for their determination}

The anthracycline structure consists of the tetracyclic aglycone (adriamycinone) and the sugar moiety, usually daunosamine (Fig. 1). The aglycone serves as the chromophore (light absorption at $\lambda=400$ $500 \mathrm{~nm}$ ) and fluorescent moiety (light emission at $\lambda=$ 500-600 nm upon excitation). Their chemical properties, e.g. fluorescence, enable their quantification in biological samples. However, their interaction with DNA leading to the fluorescence quenching complicates the direct determination of the anthracycline level in the cells (Rizzo et al. 1989). The anthracycline binding to plasma proteins can also lead to the imprecise results (Chassany et al. 1996).

\section{Sample handling}

For the precise quantification it is crucial to handle the samples containing anthracyclines with care, including used labware, their exposure to light and their stability in aqueous solutions.

Firstly, the anthracyclines sorb strongly to a variety of materials. Polypropylene labware and containers should be preferred to glass (Tomlinson and Malspeis 1982). Secondly, they are photolabile and thermolabile (Wood et al. 1990). Therefore, their exposure to light and high temperature should be minimized. Finally, the stability of anthracyclines and their metabolites in aqueous solutions, concerning biological samples, is relatively low (Beijnen et al. 1986). Thus, the biological samples have to be stored at $-20^{\circ} \mathrm{C}$ in the dark.

Not only is the active agent sensitive, but also the anthracycline nanocarriers themselves might be susceptible to the rapid degradation and the subsequent undesired drug leakage during sample preparation or storage under certain conditions. The nanocarriers based on self-assembled structures like liposome membranes or polymeric micelles can be disrupted by reagents or solvents routinely used during the drug determination and quantification methods. For example, the detergents, e.g. Triton X 100, interact with the liposome membranes (López et al. 1998). The micelle-based nanocarriers are highly sensitive to the change of $\mathrm{pH}$, ionic strength, dilution etc. which can occur during the sample preparation, e.g. its deproteinization (Owen et al. 2012).

The drug leakage from the nanocarrier structure should not occur when the anthracycline is covalently bound to the system structure. Nevertheless, the attention should be paid to the nature of the spacer and its degradation mechanisms. The nanocarriers with the drugs bound via $\mathrm{pH}$-sensitive spacers, e.g. hydrazone bonds, should be kept in the aqueous solution of neutral or slightly basic $\mathrm{pH}$ (Etrych et al. 2002). The addition of the non-selective proteases, e.g. trypsin, should be avoided when handling with the spacers degradable by lysosomal or other proteases (Ulbrich et al. 1981, Šubr et al. 1992). Therefore, the application of the published methods for the new nanocarriers should be considered in detail.

\section{Sample preparation and anthracycline isolation}

The majority of the instrumental methods determining the drug presence or content in biological samples require the sample pretreatment which consists of four major strategies - cell disruption, deproteinization, liquid-liquid extraction (LLE) or solid phase extraction (SPE) and their combination.

Intracellularly localized anthracyclines may be inaccessible for quantification. The analysis methods, e.g. HPLC, utilize analyte solutions, therefore the drug entrapped in precipitated cells will not be determined. In addition, the DNA-anthracycline complex formation can lead to the deceptive results as well. Several additives and mechanical techniques have been applied to disrupt the cellular membrane and DNA-drug complexes. The partial disruption of the cellular membranes occurs after adding the deproteinization agents and organic solvents during LLE. The enhanced cellular disruption can be achieved by detergents (Triton X-100), proteinases, ultrasound or their combination (Andersen et al. 1994). The DNAanthracycline complex dissociates upon the exposure to sodium dodecyl sulphate (Rizzo et al. 1989) or DNAse (Sakai-Kato et al. 2010).

The biological fluids are directly deproteinized using organic solvents (acetonitrile), metal ions (zinc sulphate), acid (perchloric acid) or salt (ammonium sulphate). When analyzing human blood the choice of the anticoagulant is essential, since heparin has been proved 
to interfere with the DOX measurements (Kümmerle et al. 2003). The tissue samples are generally mechanically homogenized, diluted with a particular buffer and deproteinized subsequently (Maudens et al. 2011). After deproteinization and centrifugation the samples can be directly analyzed (Álvarez-Cedrón et al. 1999).

Another approach consists of LLE (with or without prior deproteinization) using immiscible organic solvents, mainly halogenated solvents (Etrych et al. 2011). At first the sample $\mathrm{pH}$ is adjusted to 8.5-9.5 in order to convert anthracycline salts to the hydrophobic anthracycline bases. The extraction is followed either by organic phase evaporation and dilution of the evaporate in smaller volumes (Wall et al. 2007) or by backextraction into the small volume of the aqueous solution (Gilbert et al. 2005). The redissolved analyte is predominantly analyzed using HPLC with the fluorescence detector (Xiong et al. 2005). LLE is widely used for the sample preparation. The sample $\mathrm{pH}$ adjustment, the choice of the organic solvent suitable for the analyte and extraction conditions lead to high extraction coefficients. However, the simultaneous determination of diverse anthracyclines and their metabolites with different hydro-lipophilicity may provide misleading results since some analytes will be extracted in the higher or lower amount.

The anthracyclines loaded to the nanocarriers physically are likely to be transferred to the organic phase with the released drug. Therefore, the total amount of the anthracycline can be determined in the biological samples using LLE (Li et al. 2009). The anthracyclines covalently bound to the hydrophilic polymers stay in the aqueous phase. Firstly, the released drug is extracted from the sample whose $\mathrm{pH}$ is adjusted to mild basic. Then, the polymer bound and free anthracyclines are hydrolyzed to the aglycone and the total drug amount is determined (Fraier et al. 1995).

During solid phase extraction the aqueous analyte solutions from biological samples are applied on the solid phase, usually reversed-phase C18 (Lachatre et al. 2000), C8 (Nicholls et al. 1992), C2 (Buehler et al. 1999) sorbents or polymeric Oasis HLB (Difrancesco et al. 2007) and MCX (Krogh-Madsen et al. 2010) sorbents. The analyte is retained on the solid phase and the biological impurities are washed out using water or buffers (Maudens et al. 2011). The analyte is subsequently eluted by organic solvents, e.g. acetonitrile, chloroform or their combination, and the eluate is usually analyzed. The online elution by HPLC mobile phase can be performed (Rudolphi et al. 1995).

\section{Instrumental analysis}

Various instrumental techniques have been utilized to determine the presence of anthracyclines in cells, e.g. flow cytometry (FC), fluorescence microscopy (FM), laser scanning microscopy (LSCM), spectrofluorometry and chromatographic methods. These techniques are usually based on the anthracycline fluorescent properties. FM, LSCM and FC are widely used methods which offer in situ determination of drug fluorescence and its intracellular localization in ,samples without pretreatment". These approaches are combined in many studies or supplemented with quantitative anthracycline determination, e.g. by HPLC.

Fluorescent microscopy and confocal laser scanning microscopy techniques

Microscopic methods offer the detailed view of anthracycline uptake and intracellular localization after administration of free drugs or drug nanocarriers. The LSCM is a preferable method in comparison with FC, because it provides high resolution images of the anthracycline subcellular distribution in the cell lines (Coley et al. 1993). LSCM is a common method for evaluation of the intracellular localization of various types of anthracycline nanocarriers administered in vitro (Janes et al. 2001, Luo et al. 2002, Dreher et al. 2003, Cuong et al. 2010).

The drug distribution within cellular organelles can vary when the free drug or the drug bearing nanocarrier, e.g. protein conjugates with DOX, is added to the cell culture. The precise determination of the drug localization helps to clarify the mechanisms of action of these drug carriers. Using specific markers, e.g. for lysosomes, mitochondria, and the Golgi apparatus, it has been demonstrated that DOX from the protein conjugates was accumulated in the mitochondria and Golgi compartments, but not in the lysosomes, whereas free DOX showed a time-dependent intracellular shift from the nucleus to mitochondria and the Golgi apparatus (Beyer et al. 2001).

In many cases the samples were chemically pretreated before testing. Their fixation can keep samples preserved for later observation; on the other hand, changes of the cell morphology, drug fluorescence or drug localization in cell compartments can occur. The most usual fixation of cells is with $2-4 \%$ paraformaldehyde (Jin et al. 2012, Wu et al. 2012).

The drug quantification by these techniques is insufficient and can be influenced by many factors, e.g. the 
fluorescent signal quenching after binding of anthracyclines to DNA. Nevertheless, the attempt to quantify the drug using LCSM, which consists in quantifying fluorescent signal intensity from microscopy pictures by Image $\mathrm{J}$ software (Meng et al. 2010), was proposed.

\section{FLIM}

Fluorescent life time microscopy (FLIM) is also used for the documentation of the anthracycline presence inside the cells. The method can detect subcellular localization of different forms of anthracyclines or their derivatives using measurement of lifetime distribution, which can differ for free or nanocarrier bound anthracyclines in diverse parts of cells (Dai et al. 2008). For example, FLIM was used to elucidate intracellular localization of polymeric conjugates based on HPMA copolymers containing DOX bound through a biodegradable spacers (Říhová et al. 2010).

\section{Flow cytometry}

Microscopic techniques are often combined with FC enabling determination of fluorescence intensity and thus providing information about the drug content. With this technique, the drug fluorescence can be also evaluated in situ (Meng et al. 2010). The precise drug quantification is complicated by the fact that binding of anthracyclines to DNA causes quenching of fluorescence emission as mentioned above. Therefore, it is questionable whether the fluorescence which the in situ assays are based on is linearly related to the drug content of cells. For this reason the combination of detection techniques is recommended. Nevertheless, some studies were focused on the verification of the applicability of FC for anthracycline quantification. The DNR content in rat bone marrow cells was determined after incubation in vitro by $\mathrm{FC}$ and measurement of $\left[{ }^{3} \mathrm{H}\right] \mathrm{DNR}$ radioactivity. They showed a linear relationship between drug-related radioactivity and fluorescence intensity over the measured drug concentration range (0.1 to $3 \mu \mathrm{g} / \mathrm{ml}$ ) (Nooter et al. 1983).

In some studies utilizing $\mathrm{FC}$ the sample fixation was also used (Xiong et al. 2005, Li et al. 2009). However, the fixation is less frequent than for microscopic techniques.

\section{Liquid chromatographic analysis}

Chromatographic analysis with the fluorescence detector is the dominant method of anthracycline quantification. The analysis requires sample pretreatment by deproteinization, LLE or SPE. The fluorescence detection is highly sensitive and enables analysis of subnanogram drug amounts (Rossi et al. 1993).

In most cases, the reversed-phase $\mathrm{C} 18$ stacionary phase is utilized, although $\mathrm{C} 8$, cyano and phenyl stacionary phase have been used, too. Isocratic or gradient mobile phases of various compositions have been published and reviewed previously (Chen et al. 2001, Maudens et al. 2011). The composition of the mobile phase for DOX, EPI and their metabolites was optimized using the solvent selectivity triangle (Nicholls et al. 1992).

Moreover, HPLC separation enables to quantify several anthracyclines or other drugs at the same time (Alhareth et al. 2012). The samples with various metabolites can be analyzed using HPLC separation coupled with electrospray tandem mass spectroscopy which can identify the metabolite chemical structure and quantify very low drug concentrations (Liu et al. 2008).

The anthracyclines separated by HPLC can be detected also by UV/VIS-spectrophotometrically (Chin et al. 2002), electrochemically (Ricciarello et al. 1998), chemiluminescently (Ahmed et al. 2009). Although the electrochemical or chemiluminescent detection of anthracyclines is sensitive, these methods are rarely used. UV spectrometrical analysis of anthracyclines is less sensitive.

In our experience, HPLC separation and subsequent fluorescence detection with precedent LLE is a highly reproducible, selective and sensitive method of quantifying the released and not released drug from the anthracycline nanocarriers (Št'astný et al. 2002, Chytil et al. 2008).

\section{Other instrumental methods}

When one anthracycline is analyzed, the overall fluorescence of the analyte solution can be measured fluorimetrically, e.g. using the microplate reader (Meng et al. 2010). Other instrumental methods have been used to analyze the drug content, e.g. Rayleigh scattering spectrometry (Liu et al. 2007), capillary electrophoresis with UV absorption detection (Gavenda et al. 2001), with laserinduced fluorescence detection (Lu et al. 2009) or with amperometric detection ( $\mathrm{Hu}$ et al. 2000). However, the majority of these studies concerned the free anthracyclines.

\section{In vitro and in vivo models used in the anthracycline biodistribution studies}

In vitro

The broad spectrum of in vitro models, mainly based on the mouse and human cell cultures, are used to 
study cellular penetration of free anthracyclines, their subcellular distribution and content in specific cell types. The in vitro models are also used to study cell uptake, release and subcellular localization of anthracyclines from nanocarriers in order to obtain preliminary data about their cytotoxicity potential and their possible application for cancer treatment. The in vitro models were often used to study the ability of various nanocarrier systems to overcome the drug resistance of cancer cells (Meng et al. 2010, Jin et al. 2012). The in vitro models are suitable for the detailed study of subcellular distribution - cytoplasmic, nuclear or membrane binding of the drug after the nanocarrier treatment (Rodrigues et al. 1999, Beyer et al. 2001).

In vivo

The anthracycline quantification in tumor tissue or other organs and body fluids after in vivo administration to animals is usually performed after dissection and ex vivo detection, e.g. by chromatographic analysis using fluorescence detection with drug isolation by LLE (Xiong et al. 2005, Li et al. 2009) or by the measurement of radioactively labeled nanocarriers as in the case of detecting the HPMA enzymatically bound Dox in body fluids and other organs (Jelinkova et al. 2003). Drug accumulation in tissues can be evaluated by FM of dissected organs or prepared organ sections (Shen et al. 2008, Chen et al. 2010). The direct in vivo visualization of the anthracycline biodistribution using fluorescence imaging is complicated due to absorption of the fluorescence signal from the anthracycline by tissues.

\section{Anthracycline nanocarriers in clinical trials}

The similar approaches of drug quantification described above were applied in several clinical studies. The anthracycline nanocarriers investigated in clinical trials or already approved for treatment of humans, e.g. PEGylated liposome with entrapped DOX (Doxil Caelyx), were reviewed here (Minotti et al. 2004). The method using LLE and subsequent HPLC analysis to quantify released and not released DOX from HPMAbased conjugates in human samples was developed (Fraier et al. 1995, Ř́hová et al. 2003). The HPLC analysis of DOX content in human plasma and urine was combined with ${ }^{123}$ I-based imaging of HPMA-based conjugate in clinical trials concerning patients with hepatoma (Julyan et al. 1999). Indeed, the anthracycline content in human samples can be measured using other methods, HPLC coupled with mass spectroscopy for simultaneous determination of anthracyclines and their metabolites (Lachatre et al. 2000) or LSCM imaging of DOX distribution in slices from tumor biopsy (Lankelma et al. 1999). However, these methods concern free anthracyclines.

\section{Conclusions}

We reviewed the recent approaches of qualitative and quantitative determination of anthracycline nanocarriers. The precise and reproducible method determining the anthracycline content in biological samples is one of the important requirements of successful introduction of novel anthracycline nanocarriers into experimental trials and into clinical practice in the future. We concentrated on the instrumental methods enabling anthracycline determination in biological samples with respect to sample handling and pretreatment. In summary, the realtime visualization of the cellular fate of the anthracycline carriers is usually performed by microscopy techniques and FACS. However, the precise quantification of the drug content within the cells using these techniques is complicated. The accurate quantification of the drug content is usually executed using HPLC devices with the fluorescence detectors after anthracycline isolation from the biological sample by deproteinization, LLE or SPE.

\section{Conflict of Interest}

There is no conflict of interest.

\section{Acknowledgements}

This work was supported by the Ministry of Education, Youth and Sports of the Czech Republic (Grant No.EE2.3.30.0029) and by the project "BIOCEV Biotechnology and Biomedicine Centre of the Academy of Sciences and Charles University" (CZ.1.05/1.1.00/ 02.0109), from the European Regional Development Fund.

\section{References}

AHMED S, KISHIKAWA N, OHYAMA K, WADA M, NAKASHIMA K, KURODA N: Selective determination of doxorubicin and doxorubicinol in rat plasma by HPLC with photosensitization reaction followed by chemiluminescence detection. Talanta 78: 94-100, 2009. 
ALHARETH K, VAUTHIER C, GUEUTIN C, PONCHEL G, MOUSSA F: HPLC quantification of doxorubicin in plasma and tissues of rats treated with doxorubicin loaded poly(alkylcyanoacrylate) nanoparticles. J Chromatogr B 887-888: 128-132, 2012.

ÁLVAREZ-CEDRÓN L, SAYALERO ML, LANAO JM: High-performance liquid chromatographic validated assay of doxorubicin in rat plasma and tissues. J Chromatogr B Biomed Sci Appl 721: 271-278, 1999.

ANDERSEN A, WARREN DJ, SLORDAL L: Quantitation of cell-associated doxorubicin by high-performance liquidchromatography after enzymatic desequestration. Cancer Chemoth Pharmacol 34: 197-202, 1994.

ANDERSON AB, GERGEN J, ARRIAGA EA: Detection of doxorubicin and metabolites in cell extracts and in single cells by capillary electrophoresis with laser-induced fluorescence detection. J Chromatogr B 769: 97-106, 2002.

BEIJNEN JH, VAN DER HOUWEN OAGJ, UNDERBERG WJM: Aspects of the degradation kinetics of doxorubicin in aqueous solution. Int J Pharm 32: 123-131, 1986.

BEYER U, ROTHEN-RUTISHAUSER B, UNGER C, WUNDERLI-ALLENSPACH H, KRATZ F: Differences in the intracellular distribution of acid-sensitive doxorubicin-protein conjugates in comparison to free and liposomal formulated doxorubicin as shown by confocal microscopy. Pharm Res 18: 29-38, 2001.

BUEHLER PW, ROBLES SJ, ADAMI GR, GAJEE R, NEGRUSZ A: Analysis of doxorubicin in cell culture media and human plasma using solid phase extraction and HPLC. Chromatographia 49: 557-561, 1999.

CHASSANY O, URIEN S, CLAUDEPIERRE P, BASTIAN G, TILLEMENT J-P: Comparative serum protein binding of anthracycline derivatives. Cancer Chemother Pharmacol 38: 571-573, 1996.

CHEN C-L, THOEN KK, UCKUN FM: High-performance liquid chromatographic methods for the determination of topoisomerase II inhibitors. J Chromatogr B Biomed Sci Appl 764: 81-119, 2001.

CHEN Y, BATHULA SR, LI J, HUANG L: Multifunctional nanoparticles delivering small interfering RNA and doxorubicin overcome drug resistance in cancer. J Biol Chem 285: 22639-22650, 2010.

CHIN DL, LUM BL, SIKIC BI: Rapid determination of PEGylated liposomal doxorubicin and its major metabolite in human plasma by ultraviolet-visible high-performance liquid chromatography. J Chromatogr B 779: 259-269, 2002.

CHYTIL P, ETRYCH T, KOŇÁK Č, ŠÍROVÁ M, MRKVAN T, BOUČEK J, ŘÍHOVÁ B, ULBRICH K: New HPMA copolymer-based drug carriers with covalently bound hydrophobic substituents for solid tumour targeting. J Control Release 127: 121-130, 2008.

COLEY HM, AMOS WB, TWENTYMAN PR, WORKMAN P: Examination by laser scanning confocal fluorescence imaging microscopy of the subcellular localisation of anthracyclines in parent and multidrug resistant cell lines. Br J Cancer 67: 1316-1323, 1993.

COOMBS CC, TAVAKKOLI M, TALLMAN MS: Acute promyelocytic leukemia: where did we start, where are we now, and the future. Blood Cancer J 5: e304, 2015.

CUONG N-V, HSIEH M-F, CHEN Y-T, LIAU I: Synthesis and characterization of PEG-PCL-PEG triblock copolymers as carriers of doxorubicin for the treatment of breast cancer. J Appl Polym Sci 117: 3694-3703, 2010.

DAI X, YUE Z, ECCLESTON ME, SWARTLING J, SLATER NKH, KAMINSKI CF: Fluorescence intensity and lifetime imaging of free and micellar-encapsulated doxorubicin in living cells. Nanomed Nanotechnol Biol Med 4: 49-56, 2008.

DEEPA K, SINGHA S, PANDA T: Doxorubicin nanoconjugates. J Nanosci Nanotechnol 14: 892-904, 2014.

DiFRANCESCO R, GRIGGS JJ, DONNELLY J, DiCENZO R: Simultaneous analysis of cyclophosphamide, doxorubicin and doxorubicinol by liquid chromatography coupled to tandem mass spectrometry. J Chromatogr B 852: 545-553, 2007.

DREHER MR, RAUCHER D, BALU N, MICHAEL COLVIN O, LUDEMAN SM, CHILKOTI A: Evaluation of an elastin-like polypeptide-doxorubicin conjugate for cancer therapy. J Control Release 91: 31-43, 2003.

ETRYCH T, CHYTIL P, JELÍNKOVÁ M, ŘÍHOVÁ B, ULBRICH K: Synthesis of HPMA copolymers containing doxorubicin bound via a hydrazone linkage. effect of spacer on drug release and in vitro cytotoxicity. Macromol Biosci 2: 43-52, 2002. 
ETRYCH T, KOVAR L, STROHALM J, CHYTIL P, RIHOVA B, ULBRICH K: Biodegradable star HPMA polymerdrug conjugates: Biodegradability, distribution and anti-tumor efficacy. J Control Release 154: 241-248, 2011.

FRAIER D, FRIGERIO E, PIANEZZOLA E, STROLIN BENEDETTI M, CASSIDY J, VASEY P: A sensitive procedure for the quantitation of free and N-(2-hydroxypropyl)methacrylamide polymer-bound doxorubicin (PK1) and some of its metabolites, 13-dihydrodoxorubicin, 13-dihydrodoxorubicinone and doxorubicinone, in human plasma and urine by reversed-phase HPLC with fluorimetric detection. $J$ Pharm Biomed Anal 13: 625-633, 1995.

GAVENDA A, SEVCIK J, PSOTOVA J, BEDNAR P, BARTAK P, ADAMOVSKY P, SIMANEK V: Determination of anthracycline antibiotics doxorubicin and daunorubicin by capillary electrophoresis with UV absorption detection. Electrophoresis 22: 2782-2785, 2001.

GILBERT CM, MCGEARY RP, FILIPPICH LJ, NORRIS RLG, CHARLES BG: Simultaneous liquid chromatographic determination of doxorubicin and its major metabolite doxorubicinol in parrot plasma. J Chromatogr B $\mathbf{8 2 6}$ : 273-276, 2005.

GOREN D, HOROWITZ AT, TZEMACH D, TARSHISH M, ZALIPSKY S, GABIZON A: Nuclear delivery of doxorubicin via folate-targeted liposomes with bypass of multidrug-resistance efflux pump. Clin Cancer Res $\mathbf{6}$ : 1949-1957, 2000.

HU Q, ZHANG L, ZHOU T, FANG Y: Determination of daunorubicin in human urine by capillary zone electrophoresis with amperometric detection. Anal Chim Acta 416: 15-19, 2000.

JANES KA, FRESNEAU MP, MARAZUELA A, FABRA A, ALONSO MAJ: Chitosan nanoparticles as delivery systems for doxorubicin. $J$ Control Release 73: 255-267, 2001.

JELINKOVA M, STROHALM J, ETRYCH T, ULBRICH K, RIHOVA B: Starlike vs. classic macromolecular prodrugs: two different antibody-targeted HPMA copolymers of doxorubicin studied in vitro and in vivo as potential anticancer drugs. Pharm Res 20: 1558-1564, 2003.

JIN Y-H, HU H-Y, QIAO M-X, ZHU J, QI J-W, HU C-J, ZHANG Q, CHEN D-W: pH-sensitive chitosan-derived nanoparticles as doxorubicin carriers for effective anti-tumor activity: preparation and in vitro evaluation. Colloid Surf B Biointerfaces 94: 184-191, 2012.

JULYAN PJ, SEYMOUR LW, FERRY DR, DARYANI S, BOIVIN CM, DORAN J, DAVID M, ANDERSON D, CHRISTODOULOU C, YOUNG AM, HESSLEWOOD S, KERR DJ: Preliminary clinical study of the distribution of HPMA copolymers bearing doxorubicin and galactosamine. J Control Release 57: 281-290, 1999.

KRATZ F, BEYER U, ROTH T, TARASOVA N, COLLERY P, LECHENAULT F, CAZABAT A, SCHUMACHER P, UNGER C, FALKEN U: Transferrin conjugates of doxorubicin: Synthesis, characterization, cellular uptake, and in vitro efficacy. $J$ Pharm Sci 87: 338-346, 1998.

KROGH-MADSEN M, HANSEN SH, HONORÉ PH: Simultaneous determination of cytosine arabinoside, daunorubicin and etoposide in human plasma. J Chromatogr B 878: 1967-1972, 2010.

KÜMMERLE A, KRUEGER T, DUSMET M, VALLET C, PAN Y, RIS HB, DECOSTERD LA: A validated assay for measuring doxorubicin in biological fluids and tissues in an isolated lung perfusion model: matrix effect and heparin interference strongly influence doxorubicin measurements. J Pharm Biomed Anal 33: 475-494, 2003.

LACHATRE F, MARQUET P, RAGOT S, GAULIER JM, CARDOT P, DUPUY JL: Simultaneous determination of four anthracyclines and three metabolites in human serum by liquid chromatography-electrospray mass spectrometry. J Chromatogr B Biomed Sci Appl 738: 281-291, 2000.

LAGINHA KM, VERWOERT S, CHARROIS GJ, ALLEN TM: Determination of doxorubicin levels in whole tumor and tumor nuclei in murine breast cancer tumors. Clin Cancer Res 11: 6944-6949, 2005.

LANKELMA J, DEKKER H, LUQUE FR, LUYKX S, HOEKMAN K, VAN DER VALK P, VAN DIEST PJ, PINEDO HM: Doxorubicin gradients in human breast cancer. Clin Cancer Res 5: 1703-1707, 1999.

LI X, DING L, XU Y, WANG Y, PING Q: Targeted delivery of doxorubicin using stealth liposomes modified with transferrin. Int J Pharm 373: 116-123, 2009.

LIU S, WANG F, LIU Z, HU X, YI A, DUAN H: Resonance Rayleigh scattering spectra for studying the interaction of anthracycline antineoplastic antibiotics with some anionic surfactants and their analytical applications. Anal Chim Acta 601: 101-107, 2007. 
LIU Y, YANG Y, LIU X, JIANG T: Quantification of pegylated liposomal doxorubicin and doxorubicinol in rat plasma by liquid chromatography/electrospray tandem mass spectroscopy: Application to preclinical pharmacokinetic studies. Talanta 74: 887-895, 2008.

LOADMAN PM, CALABRESE CR: Separation methods for anthraquinone related anti-cancer drugs. J Chromatogr $B$ Biomed Sci Appl 764: 193-206, 2001.

LÓPEZ O, DE LA MAZA A, CODERCH L, LÓPEZ-IGLESIAS C, WEHRLI E, PARRA JL: Direct formation of mixed micelles in the solubilization of phospholipid liposomes by Triton X-100. FEBS Lett 426: 314-318, 1998.

LU H, YUAN G, HE Q, CHEN H: Rapid analysis of anthracycline antibiotics doxorubicin and daunorubicin by microchip capillary electrophoresis. Microchem J 92: 170-173, 2009.

LUO Y, BERNSHAW N, LU Z-R, KOPECEK J, PRESTWICH G: Targeted delivery of doxorubicin by HPMA copolymer-hyaluronan bioconjugates. Pharm Res 19: 396-402, 2002.

MATSUMURA Y, MAEDA H: A new concept for macromolecular therapeutics in cancer chemotherapy: mechanism of tumoritropic accumulation of proteins and the antitumor agent smancs. Cancer Res 46: 6387-6392, 1986.

MAUDENS KE, STOVE CP, LAMBERT WE: Quantitative liquid chromatographic analysis of anthracyclines in biological fluids. J Chromatogr B Analyt Technol Biomed Life Sci 879: 2471-2486, 2011.

MENG H, LIONG M, XIA T, LI Z, JI Z, ZINK JI, NEL AE: Engineered design of mesoporous silica nanoparticles to deliver doxorubicin and P-glycoprotein siRNA to overcome drug resistance in a cancer cell line. ACS Nano 4: 4539-4550, 2010.

MINOTTI G, MENNA P, SALVATORELLI E, CAIRO G, GIANNI L: Anthracyclines: molecular advances and pharmacologic developments in antitumor activity and cardiotoxicity. Pharmacol Rev 56: 185-229, 2004.

NICHOLLS G, CLARK BJ, BROWN JE: Solid-phase extraction and optimized separation of doxorubicin, epirubicin and their metabolites using reversed-phase high-performance liquid chromatography. $J$ Pharm Biomed Anal 10: 949-957, 1992.

NAGASAWA K, TSUMURA A, NOMIYAMA M, OHNISHI N, YOKOYAMA T: Transport mechanism of pirarubicin in human mononuclear cells. Biol Pharm Bull 19: 1203-1209, 1996.

NOOTER K, VAN DEN ENGH G, SONNEVELD P: Quantitative flow cytometric determination of anthracycline content of rat bone marrow cells. Cancer Res 43: 5126-5130, 1983.

OWEN SC, CHAN DPY, SHOICHET MS: Polymeric micelle stability. Nano Today 7: 53-65, 2012.

PARK J, FONG PM, LU J, RUSSELL KS, BOOTH CJ, SALTZMAN WM, FAHMY TM: PEGylated PLGA nanoparticles for the improved delivery of doxorubicin. Nanomed Nanotechnol Biol Med 5: 410-418, 2009.

PÉREZ-RUIZ T, MARTÍNEZ-LOZANO C, SANZ A, BRAVO E: Simultaneous determination of doxorubicin, daunorubicin, and idarubicin by capillary electrophoresis with laser-induced fluorescence detection. Electrophoresis 22: 134-138, 2001.

RICCIARELLO R, PICHINI S, PACIFICI R, ALTIERI I, PELLEGRINI M, FATTOROSSI A, ZUCCARO P: Simultaneous determination of epirubicin, doxorubicin and their principal metabolites in human plasma by high-performance liquid chromatography and electrochemical detection. J Chromatogr B Biomed Sci Appl 707: 219-225, 1998.

RIZZO V, SACCHI N, MENOZZI M: Kinetic studies of anthracycline-DNA interaction by fluorescence stopped flow confirm a complex association mechanism. Biochemistry 28: 274-282, 1989.

RODRIGUES PCA, BEYER U, SCHUMACHER P, ROTH T, FIEBIG HH, UNGER C, MESSORI L, ORIOLI P, PAPER DH, MÜLHAUPT R, KRATZ F: Acid-sensitive polyethylene glycol conjugates of doxorubicin: preparation, in vitro efficacy and intracellular distribution. Bioorgan Med Chem 7: 2517-2524, 1999.

ROSSI DT, PHILLIPS BA, BALDWIN JR, NARANG PK: Improved methodology for subnanogram quantitation of doxorubicin and its 13-hydroxy metabolite in biological fluids by liquid chromatography. Anal Chim Acta 271: 59-68, 1993.

RUDOLPHI A, VIELHAUER S, BOOS K-S, SEIDEL D, BATHGE I-M, BERGER H: Coupled-column liquid chromatographic analysis of epirubicin and metabolites in biological material and its application to optimization of liver cancer therapy. J Pharm Biomed Anal 13: 615-623, 1995. 
ŘÍHOVÁ B, STROHALM J, PRAUSOVA J, KUBACKOVA K, JELINKOVA M, ROZPRIMOVA L, SIROVA M, PLOCOVA D, ETRYCH T, SUBR V, MRKVAN T, KOVAR M, ULBRICH K: Cytostatic and immunomobilizing activities of polymer-bound drugs: experimental and first clinical data. $J$ Control Release 91: 1-16, 2003.

ŘÍHOVÁ B, ETRYCH T, ŠÍROVÁ M, KOVÁŘ L, HOVORKA O, KOVÁŘ M, BENDA A, ULBRICH K: Synergistic action of doxorubicin bound to the polymeric carrier based on $\mathrm{N}$-(2-hydroxypropyl)methacrylamide copolymers through an amide or hydrazone bond. Mol Pharm 7: 1027-1040, 2010.

SAKAI-KATO K, SAITO E, ISHIKURA K, KAWANISHI T: Analysis of intracellular doxorubicin and its metabolites by ultra-high-performance liquid chromatography. J Chromatogr B 878: 1466-1470, 2010.

SHEN F, CHU S, BENCE AK, BAILEY B, XUE X, ERICKSON PA, MONTROSE MH, BECK WT, ERICKSON LC: Quantitation of doxorubicin uptake, efflux, and modulation of multidrug resistance (MDR) in MDR human cancer cells. J Pharmacol Exp Ther 324: 95-102, 2008.

SHUAI X, AI H, NASONGKLA N, KIM S, GAO J: Micellar carriers based on block copolymers of poly( $\varepsilon$ caprolactone) and poly(ethylene glycol) for doxorubicin delivery. $J$ Control Release 98: 415-426, 2004.

SPETH PA, RAIJMAKERS RA, BOEZEMAN JB, LINSSEN PC, DE WITTE TJ, WESSELS HM, HAANEN C: In vivo cellular adriamycin concentrations related to growth inhibition of normal and leukemic human bone marrow cells. Eur J Cancer Clin Oncol 24: 667-674, 1988.

ŠŤASTNÝ M, PLOCOVÁ D, ETRYCH T, ULBRICH K, ŘÍHOVÁ B: HPMA-hydrogels result in prolonged delivery of anticancer drugs and are a promising tool for the treatment of sensitive and multidrug resistant leukaemia. Eur J Cancer 38: 602-608, 2002.

ŠUBR V, STROHALM J, ULBRICH K, DUNCAN R, HUME IC: Polymers containing enzymatically degradable bonds, XII. Effect of spacer structure on the rate of release of daunomycin and adriamycin from poly [N-(2hydroxypropyl)-methacrylamide] copolymer drug carriers in vitro and antitumour activity measured in vivo. J Control Release 18: 123-132, 1992.

TOMLINSON E, MALSPEIS L: Concomitant adsorption and stability of some anthracycline antibiotics. $J$ Pharm Sci 71: 1121-1125, 1982.

ULBRICH K, STROHALM J, KOPEČEK J: Polymers containing enzymatically degradable bonds, 3. Poly[N-(2hydroxypropyl)methacrylamide] chains connected by oligopeptide sequences cleavable by trypsin. Makromol Chem 182: 1917-1928, 1981.

USTER PS, WORKING PK, VAAGE J: Pegylated liposomal doxorubicin (DOXIL®, CAELYX®) distribution in tumour models observed with confocal laser scanning microscopy. Int J Pharm 162: 77-86, 1998.

WALL R, MCMAHON G, CROWN J, CLYNES M, O’CONNOR R: Rapid and sensitive liquid chromatographytandem mass spectrometry for the quantitation of epirubicin and identification of metabolites in biological samples. Talanta 72: 145-154, 2007.

WICKI A, WITZIGMANN D, BALASUBRAMANIAN V, HUWYLER J: Nanomedicine in cancer therapy: Challenges, opportunities, and clinical applications. J Control Release 200: 138-157, 2015.

WOOD MJ, IRWIN WJ, SCOTT DK: Photodegradation of doxorubicin, daunorubicin and epirubicin measured by high-performance liquid chromatography. J Clin Pharm Ther 15: 291-300, 1990.

WU Z, ZENG X, ZHANG Y, FELIU N, LUNDBERG P, FADEEL B, MALKOCH M, NYSTRÖM AM: Lineardendritic polymeric amphiphiles as carriers of doxorubicin - In vitro evaluation of biocompatibility and drug delivery. J Polym Sci A Polym Chem 50: 217-226, 2012.

XIONG X-B, HUANG Y, LU W-L, ZHANG X, ZHANG H, NAGAI T, ZHANG Q: Enhanced intracellular delivery and improved antitumor efficacy of doxorubicin by sterically stabilized liposomes modified with a synthetic RGD mimetic. J Control Release 107: 262-275, 2005.

YANG SR, LEE HJ, KIM J-D: Histidine-conjugated poly(amino acid) derivatives for the novel endosomolytic delivery carrier of doxorubicin. $J$ Control Release 114: 60-68, 2006.

YOO HS, PARK TG: Biodegradable polymeric micelles composed of doxorubicin conjugated PLGA-PEG block copolymer. J Control Release 70: 63-70, 2001.

ZAGOTTO G, GATTO B, MORO S, SISSI C, PALUMBO M: Anthracyclines: recent developments in their separation and quantitation. J Chromatogr B Biomed Sci Appl 764: 161-171, 2001. 